\title{
The relationship between hope and optimism, ethical leadership and person-organisation fit
}

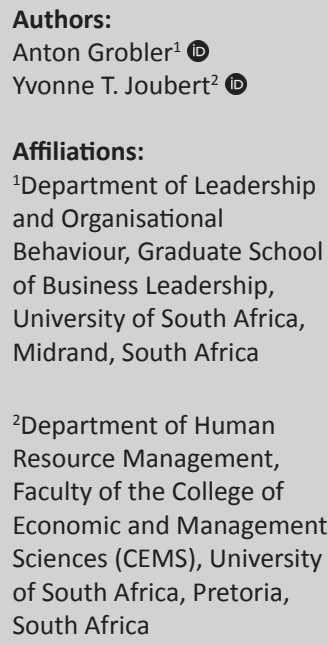

Research Project Registration: Project Number: 001 of 2016

Corresponding author:

Yvonne Joubert,

joubeyt@unisa.ac.za

Dates:

Received: 07 Nov. 2018

Accepted: 10 Oct. 2019

Published: 04 May 2020

How to cite this article: Grobler, A. \& Joubert, Y.T., 2020, 'The relationship between hope and optimism, ethical leadership and person-organisation fit', South African Journal of Economic and Management Sciences 23(1), a2872. https://doi.org/10.4102/ sajems.v23i1.2872

\section{Copyright:}

(C) 2020. The Authors. Licensee: AOSIS. This work is licensed under the Creative Commons Attribution License.
Background: Ethical leadership is viewed as a challenge globally, with person-organisation fit, as well as hope and optimism, being regarded as an essential element of employee well-being and, ultimately, productivity.

Aim: The aim of this study is to examine the relationship between the employees' perceived ethical leadership in the organisation and the employees' person-organisation fit, hope and optimism.

Setting: Employees of 30 organisations in South Africa were sampled and there were 1663 respondents.

Methods: A typical positivist methodology - based on an empirical approach, using a crosssectional design and the quantitative analysis of the data obtained from the surveys - was utilised in this study.

Results: It was found that there is a strong, positive relationship between ethical leadership and hope and optimism (as a composite construct). It was further found that personorganisation fit mediates this relationship.

Conclusion: Recommendations were made to enhance hope and optimism from an institutional (including human resources) as well as leadership level. Recommendations were also made for further research.

Keywords: Ethical leadership; Hope; Micro, meso, macro levels; Optimism; Personorganisation fit.

\section{Introduction}

Avey (2014) identified a gap in the psychological capital research (with hope and optimism being two of the four basic components), as he believes that there is a lack of research in terms of antecedents of psychological capital. Positive organisational behaviour variables, like psychological capital dimensions (including hope and optimism), are often studied from an independent variable position; in other words, by studying their impact on other variables. Avey (2014) identifies a need to study organisational as well as individual processes that contribute to psychological capital. By the adoption of the meso framework as conceptual framework, hope and optimism is studied as the dependent variable, with the impact of ethical leadership and person-organisation fit (and these in combination) as antecedents. The rationale for this approach is based on the notion that hope and optimism is regarded a state-like variable, which can be developed, and it is susceptible to environmental influences. Not only does research on the antecedents of hope and optimism contribute to the academic body of knowledge, but it can also be used to develop strategies and actions to enhance hope and optimism in the workplace.

Consequently, the aim of this study is to examine the relationship between the employees' perceived ethical leadership in the organisation and the employees' person-organisation fit, hope and optimism. Hope and optimism in the workplace (collectively referred to positive work expectations) is studied as a composite variable, based on the work of Grobler and Joubert (2018). They found that hope and optimism (originally two separate dimensions of psychological capital) loaded onto one factor, referred to as hope and optimism in this article. It is acknowledged that there are theoretical differences between the two constructs, and these will be discussed shortly, but the communality between them seems to resort in their expectancy of goal attainment. It is for this reason that the line of argument of this study is moved to hope and optimism as positive work expectations, instead of as separate and distinct constructs. 
This study is approached from a positively focused organisational perspective which is intended to foster the development of a holistic understanding of employee and organisational functioning (Dawkins 2014), with specific reference to positive work expectations. It can be approached from the perspectives of two broad and distinct schools, namely positive organisational scholarship and positive organisational behaviour. Positive organisational scholarship focuses on positive dynamics, processes and patterns that lead to organisational effectiveness (Cameron, Dutton \& Quinn 2003), and is thus on the macro level of an organisation. Positive organisational behaviour, on the other hand, is the study and application of employees' psychological strengths and capabilities that can be measured, managed and developed for enhanced performance in the workplace (Luthans 2002). It thus represents variables on the micro (or individual) level of an organisation. The interaction and interrelatedness of the variables under investigation is conceptualised in terms of the macro, meso and micro hierarchical levels, in accordance with the so-called meso framework. Ethical leadership, person-organisation fit, and hope and optimism are represented on the macro, meso and micro hierarchical levels. This study is thus based on multiple levels in terms of the interrelated conceptualisation, although the level of analysis is employee perceptions, with the level of measurement being the perceptions of the constructs on the three levels.

The value contribution of this study is in terms of the model that is presented, indicating the role of ethical leadership and person-organisation fit in hope and optimism. This study can contribute on a practical level to identify and confirm variables that impact on hope and optimism, and to make practical recommendations to enhance hope and optimism (as it can be developed). This is important as hope and optimism has been found to be a predictor of employee wellness, productivity and satisfaction and so on, all contributing to organisational positivity and, from an interrelated meso approach, integrating the two schools of thought, namely positive organisational behaviour and positive organisational scholarship.

\section{Literature review}

In these turbulent geopolitical and economic times, all countries around the globe find themselves teetering between fear and despair on the one hand, and hope and opportunity on the other. Why is South Africa a good example of this? The country experienced a turning point in its history more than 20 years ago - significant not only because it resulted in the first democratic election of a black majority government and because it marked the end of apartheid, but also because it initiated a paradigm shift for organisational leadership. In the intervening years, however, South Africa has reached a state of crisis brought about largely by a shortage of good leaders, something that has become painfully evident since the 2017 Cabinet rearrangement. Added to this, recent incidents (within both the private and the public sectors) of leaders being involved in tax evasion, cadre deployment, money laundering, falsifying qualifications, and financial manipulation, to name just a few, have had a serious negative impact on organisational as well as individual well-being (Grobler 2017). This runs directly counter to South Africa's need for ethical leaders who will render good service and to give the nation hope, rather than focusing on self-enrichment and power (Reddy 2017). To illustrate the seriousness of the situation, it is noted that $22 \%$ of chief executives in South Africa, compared to only $14 \%$ globally, are concerned about possible ethical scandals (City Press 2018).

In terms of hope and optimism within an organisational context, it was found in a study (involving 28 participating countries) that a total of $76 \%$ of the respondents are of the view that 2018 will be a better year than 2017. South Africa is one of the most optimistic countries with $85 \%$ of the respondents expecting a good year. This could be due to the recent change in the country's leadership and the promise of better economic prospects (Lindeque 2018). Hope (and optimism) is generally associated with the quality of leadership, according to Shade (2001), while Helland and Winston (2005) comment that positive forms of leadership (including ethical leadership) inspire hope. The last mentioned are of the view that hope (and optimism), as a result of effective and ethical leadership, positively contributes towards the achievement of organisational goals, because they regard effective leadership as awakening hopeful thinking.

Ethical leadership is thought to be uniquely important because of the impact leaders may have on the conduct of (others in) the organisation (De Hoogh \& Den Hartog 2008). We argue that ethical leadership behaviour will contribute to employees' optimism about their organisation and is mediated by their perceptions of fit within the organisation. To our knowledge, this has not yet been tested. We further believe that ethical leadership points organisational members towards mutual goals and objectives and guides them on this path, something that can only benefit the organisation, its members, stakeholders and society (De Hoogh \& Den Hartog 2008). Moreover, through ethical behaviour, leaders reap the loyalty and confidence of their followers and this, in turn, leads to employees being more hopeful, optimistic and positive about their work and organisation. When leaders are unethical, and their moral integrity is in doubt, their followers will most likely not work towards achieving organisational goals. Ethical leaders attempt to create just work environments, they care about their followers' feelings and they strive to make fair choices. Their followers are, therefore, expected to be optimistic and positive about their work situation and the organisation.

Positive and engaged employees with high levels of hope are needed in today's extremely turbulent environment. Organisations tend to be characterised by downsizing, relentlessly advancing technology, mergers, bankruptcies and an uncertain global economy (Luthans \& Jensen 2002). Luthans and Jensen (2002) continue by saying that hopeful employees can cope and thrive in unprecedented 
environments and are effective performers in organisations. Yet, despite this knowledge, limited attention has been paid to hope within leadership studies (Helland \& Winston 2005). Hope, like leadership, arises in relationships with others and involves dialogue regarding ultimate outcomes and future orientation and it is action directed to achieve goals (Helland \& Winston 2005).

Leaders may have an impact on their followers' optimism. It is argued that followers learn optimism from their leaders' behaviour. The leader's behaviour carries positive, consistent (and ethical) information and directs followers to develop a positive outlook on the future, which results in perceptions of optimism (Lu, Xie \& Guo 2018). People with an optimistic view believe that they will have a favourable and prosperous future (Perera \& McIlveen 2014) and such people will be engaged in achieving organisational goals (Tuckey, Bakker \& Dollard 2012). Optimistic employees also experience workplace satisfaction, which means that they reach a state of work fulfilment and are able to cope with job demands ( $\mathrm{Lu}$ et al. 2018). However, according to Peterson and Seligman (2003), as well as Luthans, Youssef and Avolio (2007), the role that leadership plays in building positive behaviour, such as optimism in the workplace, has been neglected in research.

This study includes three variables, namely ethical leadership (on the macro level), hope and optimism (as part of psychological capital) (on the micro level) and personorganisation fit (on the meso level), which are discussed below.

\section{Micro-meso-macro framework on organisational behaviour research}

Before the variables are discussed, it is deemed necessary to provide a short introduction to the micro-meso-macro framework that is proposed as a conceptual framework to analyse and explain the interrelatedness of the variables. The discussion is focused specifically on the hierarchical nature of the interaction of the variables. The micro-meso-macro framework is based on the work of Dopfer, Foster and Potts (2004) and elaborated on by Dopfer (2005) and Dopfer and Potts (2008). They define three distinct levels of analytical structure which comprise the knowledge base of any economic (or organisational) system. Connections can be established through the integration of the three levels (Jeurissen 1997). House, Rousseau and Thomas-Hunt (1995) regard this framework to be universal and applicable across disciplines and phenomena. It can therefore be utilised within the broad domain of organisational behaviour and is thus deemed appropriate for this study. The interrelatedness manifests itself in that the macro-organisational phenomena are influenced by individuals and groups, as individuals enact environments, and vice versa. Conventional macroorganisational components (archetypally related to organisational behaviour) are organisational culture and climate, including leadership. The meso level (interactional) is concerned with at least two levels of analysis simultaneously, with one or more levels concerning individual or group behavioural processes, as well as one or more organisational processes, and the linking or bridging of the respective processes (House et al. 1995). It is aimed at synthesising the micro-organisational and macro-organisational processes. The micro level, within the organisational behaviour context and according to Kyriakidou and Özbilgin (2006), is all about individuals as the elementary unit of analysis, assuming fixed identities, interests, goals and preferences. It therefore represents individuals as self-subsistent entities.

\section{Positive work expectations - Hope and optimism (as micro level variable)}

Two concepts that are arguably the most widely researched within positive psychology are hope (Snyder 2002) and optimism (Scheier \& Carver 1985). According to Rand, Martin and Shea (2011), a person's physical and psychological adjustment is influenced by the extent to which goals are attained, and it is for this reason that hope and optimism are considered as important elements of well-being in general.

Snyder (2002) depicts two notions for hope: firstly that hope is obtained when goals are met and, secondly, that hope is influenced by the perceived availability of successful ways to achieve goals. Scheier and Carver (1985), on the other hand, based optimism on the expectancy-value model of motivation. Even tough expectancy varies from different goals. Scheier and Carver (1985) are of the view that people have a more diffuse sense of expectancy (also called optimism) about goals in their lives. Therefore, optimism affects the situationspecific opinions people have when they are working towards a goal. Optimistic people are inclined to expect a positive outcome no matter what the goal, whereas pessimistic people are inclined to expect a negative outcome. According to Luthans, Van Wyk and Walumbwa (2004), optimistic people are more satisfied, are motivated to work harder, persevere in the face of difficulties, have high levels of positive aspiration, see their setbacks as temporary, and analyse their personal failures.

The basic difference between optimism and hope is that optimism includes expectancies about the outcome of a situation through forces and people outside oneself, whereas hope lies within the individual (Snyder 2002). Luthans and Jensen (2002) continue by saying that, although optimism and hope share common perspectives regarding the importance of expectancies, and that both are goal-directed behaviour, the two concepts differ in expectancy. Optimistic people believe that good things will happen, but they may lack the vital ways of thinking, such as generating the new alternative ways needed to overcome hurdles and to attain the goal. According to Jahanara (2017) the differences between hope and optimism are that hope involves thoughts about an individual's own ability to attain goals, as well as ways and motivation to use this ability to reach these goals. Optimism, on the other hand, involves expectancies for outcomes in the future without the individual having control over the achieving of those outcomes.

Despite the differences, there are also similarities between hope and optimism. Hope and optimism share a common 
element, namely the belief that goals will be attained (Rand et al. 2011). These two concepts are traits that affect cognition about goals, positive and negative emotions, coping behaviours, well-being and goal attainment (Jahanara 2017). Both concepts emphasise the importance of goals and outcomes and assume that a person's behaviour is motivated by goals.

Therefore, optimism is a goal-orientated belief that a positive outcome will be achieved for now and in the future, whereas hope closely resembles optimism in that it is a goal-directed cognitive belief based on ways to attain goals (Luthans et al. 2007). In other words, an optimistic person has the willpower component of hope, but not necessarily the so-called 'way power' dimension of hope (Luthans \& Jensen 2002).

Regarding the influence of the external environment (from macro and meso variables) on hope and optimism, Seligman (2011) is of the view that individuals grow optimistic through learning from the environment. Snyder (2002) further hypothesised that hope includes endurance and is based on continuous traits such as self-referential appraisals, as well as on situation-specific thought processes about a person's ability to attain goals.

\section{Meaning of ethical leadership}

People often ask 'what is leadership?' or 'what characteristics does a good leader have?'. Good leaders are not only competent, but also ethical in their actions (Ciulla 1995). Different authors outline characteristics and attributes that pertain to good leaders (Toor \& Ofori 2009), such as integrity, trustworthiness, encouragement, character, altruism, honesty, collective motivation and justice (Holder 2019; Palanski \& Yammarino 2007; Resick et al. 2006; Toor \& Ogunlana 2008). However, studies have shown that there is more to leadership than merely attributes (Toor \& Ofori 2009). Kodish (2006) is of the view that leadership is a skill and not only the knowledge of theories. He continues by saying that it is the ability to act ethically and purposively in situations, based on experience, intuition, perception and the knowledge of universals. But what is ethical leadership? An interesting observation from Kanungo (2001) is that ethical leaders refrain from behaviours that will cause any harm to others and are engaged in behaviours that benefit others. According to Trevino and Brown (2004), ethical leadership is the promotion of ethical conduct by consciously managing and practising ethics and holding every employee accountable for it. In this research study, we accept the definition of ethical leadership by Brown, Trevino and Harrison (2005) who define ethical leadership as the demonstration of appropriate normative conduct through interpersonal relationships and personal actions, combined with Toor and Ofori's (2009) promotion of such appropriate conduct to followers through decision-making, reinforcement and two-way communication.

\section{Meaning of person-organisation fit}

Previously, literature on person-organisation (PO) fit focused more on outcomes in an organisation - such as the organisation's culture, effectiveness and structure (Schneider, Smith \& Paul 2001). More recently, however, the focus has turned to outcomes for an employee, for example employee behaviour (Arthur et al. 2006). Person-organisation fit can be defined as the compatibility between employees and organisations that occurs when: (1) one entity provides what the other one needs, (2) similar fundament characteristics are shared or (3) both (Grobler 2016; Kristof-Brown 2000). Liu, Liu and $\mathrm{Hu}$ (2010) continue by saying that PO fit is the similarity between the characteristics of the organisation and the employees' personalities, compatibility of goals between the organisation and its employees and, lastly, the consistency between the organisation's culture and its employees (Grobler 2016). Research has found that PO value fit has an effect on the employees' commitment, performance and satisfaction in an organisation (Li 2006). Pervin and Rubin (1967) are of the opinion that employees who do not fit in their organisation experience feelings of anxiety and incompetence, while those who fit have fewer negative and more positive effects. Posner (1992), on the other hand, found that $\mathrm{PO}$ value fit relates to positive work attitudes.

\section{Relationship between ethical leadership and psychological capital}

Very little research was found where ethical leadership and psychological capital were studied. Considerable research has been done specifically on authentic leadership and psychological capital. Authenticity, viewed from an ethical perspective, means being true to oneself and keeping one's word. Being true to one's word, especially when dealing with others, is an example of behavioural integrity (Leroy, Palanski \& Simons 2012). Luthans and Avolio (2003) consider authentic leadership as a construct that incorporates ethical and transformational leadership. The focus in this section is on the relationship between authentic leaders (which is closely related to ethical leadership) and psychological capital, due to the availability and relevance of such research.

Owens (2017) concluded from a study that there is a positive relationship between psychological capital and authentic leadership $(r=0.38)$. Resilience, an element of psychological capital, had a non-significant but moderate-sized relationship with self-awareness, an element of authentic leadership $(r=0.31)$. There was a non-significant but moderate-sized relationship between the total scale of psychological capital and relational transparency, another element of authentic leadership $(r=0.33)$. Hope, another element of psychological capital, had a non-significant but moderate-sized relationship with the total score of authentic leadership $(r=0.30)$.

In a study done by Du Plessis (2014), it was found that there is a low correlation between the total scores of psychological capital and authentic leadership, with a common variance of $11.5 \%$. She further found that there is a low correlation between the dimensions of authentic leadership and the dimensions of psychological capital. The relationship between optimism, an element of psychological capital, and the dimensions of authentic leadership, ranges from $r=0.13$ 
to $r=0.16$, which indicates a slight relationship between the two concepts.

\section{Relationship between ethical leadership and psychological capital}

No previous research was found that studied the direct relationship between ethical leadership and psychological capital. Related to psychological capital, it was found that there is a positive association between perceptions of ethical leadership and psychological well-being (Bedi, Alpaslan \& Green 2015). Another study, conducted by Yang (2013), concluded that ethical leadership indirectly influences an employee's life satisfaction as well as their well-being.

\section{Relationship between ethical leadership and person-organisation fit}

Similarly to the previous section, very little research was found that describes the relationship between ethical leadership and PO fit. Related to ethical leadership, Ambrose, Arnaud and Schminke (2007) examined whether the congruence between ethical values, a specific subset of values of the organisation and the values of the employee is associated with attitudinal outcomes. In this study it was found that the fit between an employee's moral development and the organisation's ethical climate relates to higher job satisfaction. It was further found that the fit between an employee's moral development and the organisation's ethical climate relates to greater organisational commitment. Further, it was found that the fit between an employee's moral development and the organisation's ethical climate relates to lower employee turnover.

Valentine, Godkin and Lucero (2002) conducted a study on the relationship between ethical context, organisational commitment and PO fit, using a sample of 304 employees. They concluded in their study that the corporate ethical values construct positively relates to PO fit $(p<0.001)$.

From the discussion about the relationship between the variables used in this study, it is clear that many untapped research opportunities exist, with specific reference to psychological capital as dependent variable. For instance, the need for future collective psychological capital research to consider not only the presence of various levels of analysis, but also the interaction across these levels has been identified (Youssef \& Luthans 2011) and greater variance can be explained in dependent variables when psychological capital components are analysed individually (Rego et al. 2010). Multilevel research allows for consideration of the consequences of behaviours crossing organisational levels (for instance across levels). Thus, a richer understanding of social phenomena, including collective psychological capital, can be developed by going beyond a single level of analysis.

The model in Figure 1 assumes a three-variable system, with two causal paths feeding into the outcome variable: the direct impact of the independent variable (Path c) and the impact of

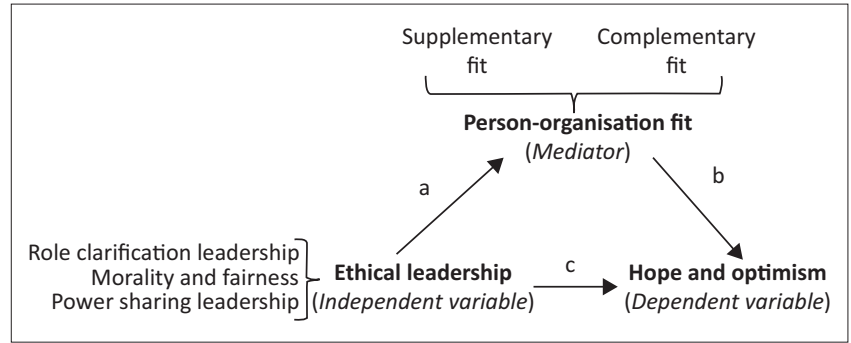

FIGURE 1: The model studies: The role of ethical leadership in hope and optimism, mediated by person-organisation fit.

the mediator (Path b). There is also a path from the independent variable to the mediator (Path a).

\section{Method}

\section{Research design}

A typical positivist methodology, based on an empirical approach and using a cross-sectional design and the quantitative analysis of the data obtained from the surveys, was utilised in this study.

\section{Sample}

Employees of 30 organisations in South Africa were sampled, with 16 of the organisations being from the private sector, including the medical, engineering, retail, construction, financial, telecommunication, pharmaceutical and information technology industries. The public sector is slightly less represented with 14 organisations, consisting of national and provincial departments, as well as local government. In each organisation, 60 employees were randomly selected to participate in the study. There were thus, potentially, 1800 individual participants. The fieldwork was done by 30 co-researchers working on a larger project in the same industry and ethical clearance was granted by the University of South Africa.

There were 1663 valid responses (after deleting all missing values case wise), thus $92.38 \%$ of the potential sample. The mean age of the respondents was 38.51 years $(S D=9.39)$, and the mean tenure in the specific organisation 8.85 years $(S D=7.65)$. The assumption can thus be made that the sample is well representative of the general work force and that the participants, in terms of age and tenure, would be able to provide an accurate assessment of their perceptions of the constructs being measured.

\section{Measuring instruments}

The respondents were requested to rate their executives' perceived levels of ethical leadership and their own levels of PO fit and hope and optimism. The three-factor Ethical Leadership Questionnaire (ELQ) developed by De Hoogh and Den Hartog (2008) was used to measure ethical leadership, the independent variable in this study. The first items relate to morality and fairness and one of the items reads 'The leaders in my organisation deserves trust, can be believed and relied upon to keep their word'. Role clarification 
leadership is the second factor and one of the items reads 'The leaders in my organisation communicate their performance expectations for group members'. Power sharing leadership, the third factor, is made up of items such as 'The leaders in my organisation will reconsider decisions on the basis of recommendations by those who report to them'. This instrument was designed to elicit respondents' reports of behaviour of leaders and uses a seven-point Likert scale. De Hoogh and Den Hartog (2008) reported Cronbach's alpha coefficients of $0.81,0.88$ and 0.78 for the respective factors in their study conducted in the Netherlands. Grobler (2017) validated the instrument for use in the South African context through three independent studies, and his results support the original conceptualisation and factorial composition, except for one item that loaded on another factor compared to the original model. He also reported Cronbach's alpha coefficients ranging from 0.82 to 0.95 . Grobler and Joubert (2018) further reported that a secondorder model with all 17 items loading directly on their respective factors (i.e. morality and fairness, role clarification leadership and power sharing leadership), which then contributes to a higher or secondary factor, namely ethical leadership, is the best-fitting model $\left(\chi^{2 / d f}(409)=5.11, \mathrm{CFI}=0.99\right.$, RMSEA $=0.033$ ). His study further yielded acceptable levels of convergent and discriminant validity of the instrument.

Person-organisation fit was measured using an instrument developed by Cable and Judge (1996). The initial instrument was multidimensional and consisted of three factors, with three items on each of the factors. However, Grobler (2016) developed a reconfigured two-factor structure, still with all nine items. The first factor, supplementary fit (organisation fit as values congruence), consists of three items, with one of the items reading 'My personal values match my organisation's values and culture'. The second factor, called complementary fit (which includes needs-supplies fit, as well as demandsabilities fit), consists of six items. Two of the items, by way of example, read 'The attributes that I look for in a job are fulfilled very well by my present job' (needs-supplies fit) and 'My personal abilities and education provide a good match with the demands that my job places on me' (demandsabilities fit). The instrument uses a five-point Likert scale. Grobler (2016) reported acceptable Cronbach's alpha coefficients (0.92 for supplementary fit and 0.89 for complementary fit) within the South African context.

Hope and optimism (as a composite variable) was measured with the psychological capital instrument developed by Luthans et al. (2007) and validated by Grobler and Joubert (2018) for the South African context. In their study, hope and optimism manifested as a combined factor (consisting of seven items) within the overall three-factor structural configuration. This composite factor hope and optimism showed good psychometric properties (Cronbach's alpha coefficient of 0.85). Typical items under hope and optimism read 'I always look on the bright side of things regarding my job' and 'At the present time, I am energetically pursuing my work goals'. The instrument uses a six-point Likert scale.

\section{Statistical analysis}

The Statistical Package for the Social Sciences (SPSS version 25), supported by Analysis of a Moment Structures (AMOS version 25), was used to analyse the data. The information regarding the distribution of the data was analysed by means of basic descriptive statistics, specifically the mean score as the precise centre of the amalgamated values and the standard deviation as the measure of variability. Skewness and kurtosis were also calculated to investigate the distribution of the data. The critical values for these two statistics are 2 and 7 (West, Finch \& Curran 1995).

The Cronbach's alpha coefficient $(\alpha)$ was calculated to test the proportional variance error and the internal consistency of the instrument. A score of $\alpha=0.70$ or higher, is generally regarded as acceptable (Clark \& Watson 1995). Convergent validity was assessed by the composite reliability (CR) and the average variance extracted (AVE), with critical values of 0.70 or higher and 0.50 or lower. The discriminant validity was determined by comparing the AVE with the maximum shared variance (MSV). Discriminant validity would be confirmed when MSV is less than AVE and where the average shared variance (ASV) is less than the AVE (Hair et al. 2010).

Due to the fact that the three variables used in this study are based on a common method, Harmon's single factor was used to assess the common method variance. It is one of the most widely-used techniques employed by researchers to assess common method variance (Podsakoff et al. 2003). Nevertheless, despite its popularity, Podsakoff et al. (2003) are of the opinion that it is not the best solution to resolving common method variance. The Harmon's single factor technique makes use of an exploratory factor analysis that loads variables onto a single factor, which is constrained so that there is no rotation (Eichhorn 2014). This new factor that has been created is not part of the final model and is developed for analysis purposes only. Thus, once it has been assessed, it may be discarded (Eichhorn 2014). After conducting a Harman's single factor test, a single factor should emerge from the factor analysis and, if it represents more than $50 \%$ of the variance, this may indicate that common method variance may be present (Eichhorn 2014).

Correlations between the constructs were calculated by means of Pearson's product moment correlations. Stepwise multiple regression analysis was used to determine the amount of variance explained by the ethical leadership construct in psychological capital when PO fit is added to the analysis. The rationale for the inclusion of $\mathrm{PO}$ fit is to determine whether it improves the model or not. The multiple regression was further utilised to determine the relative strength of the two independent variables in the prediction of the dependent variable, by studying the beta $(\beta)$ values. The tolerance, as well as variance inflation factor (VIF) values, were calculated to test for possible multicollinearity. Tolerance is an indicator of the amount of variance not explained by the other independent variable in the model and should preferably be larger than 0.10 . The VIF, on the 
other hand, is the inverse of tolerance, and values should be below 10 (Pallant 2013).

It was further decided to use structural equations analysis (by means of structural equation modelling [SEM]) in addition to the multiple regressions, as it presents some advantages over traditional multivariate techniques, according to Haenlein and Kaplan (2004). To analyse the model from a theoretical perspective, AMOS was used to perform the SEM. To clarify the meaning of mediation, a path diagram was introduced as a model for depicting a causal chain. The basic causal chain involved in mediation is diagrammed in Figure 1. To assess the model fit, several fit indexes were used, including the comparative fit index (CFI), the root mean square error of approximation (RMSEA), chisquare $\left(\chi^{2}\right)$ and the ratio of the differences in chi-square to the differences in degrees of freedom $\left(\chi^{2 / d f}\right)$. Given that there is no one acceptable cut-off value of what constitutes adequate fit, it was elected to evaluate each model and to recommend the model closest to the CFI value of 0.90, an RMSEA value of 0.05 (Byrne 2010).

An analysis to determine whether the independent variable affects the dependent variable through a mediating variable (Zhao, Lynch \& Chen 2010:205) was conducted. Mediation was assessed by focusing on the indirect effect of EL on hope and optimism, by means of bootstrapping of the confidence interval (95\% interval) as recommended by Hayes and Rockwood (2017). This procedure (as calculated by SPSS PROCESS) determined the indirect effect of ethical leadership on hope and optimism. The determination was made through the mediator ( $\mathrm{PO}$ fit) which quantifies the estimated difference in hope and optimism - which is caused by a one-unit change in ethical leadership - and where ethical leadership affects PO fit and where PO fit in turn affects hope and optimism (Hayes \& Rockwood 2017).

\section{Findings}

The descriptive statistics and the psychometric properties of the instruments are reported in Table 1.

The descriptive statistics in Table 1 show that the skewness and kurtosis values of the factors do not exceed the critical values of 2.00 and 7.00, which is an indication that the data is normally distributed. Most of the values of the ethical leadership, person-organisation fit and hope and optimism constructs and sub-factors on the skewness scale were negative, which is an indication that the distribution has relatively few small values and tails off to the left. The Cronbach's alpha coefficients of the factors are acceptable if the guideline of $\alpha>0.70$ is applied. It would thus appear that the factors possess acceptable levels of internal consistency. All the factors met the conditions of convergent validity, with all CR values higher than 0.70 and the AVE value greater than 0.50 , with the exception of hope and optimism which reported a slightly lower AVE value. Evidence of discriminant validity was also found as all the AVE values are larger than the MSV values. In addition, and in support of the notion of discriminant validity, the ASV values are also less than the AVE.

To investigate the relationship between ethical leadership, person-organisation fit and hope and optimism, a correlational analysis and a stepwise multiple regression analysis were performed. The strength and the direction of the linear relationship between the factors (and total score) of ethical leadership, person-organisation fit and hope and optimism are reported in Table 2.

All the correlation coefficients reported in Table 2 indicate a positive and statistically significant $(p \leq 0.001)$ relationship between the sub-factors of ethical leadership, person-organisation fit and hope and optimism. The purpose of this study is, however, to determine the relationship between main constructs and it is this relationship that will form the essence of the interpretation. Hope and optimism correlates with ethical leadership with $r=0.39$ and with person-organisation fit with $r=0.44$ ( $p \leq 0.001$, medium effect). There is thus a medium strength, positive relationship or association between hope and optimism and both ethical leadership and person-organisation fit. To analyse these relationships further, a stepwise multiple regression analysis was performed. The results are reported in Table 3 and Table 4.

The stepwise multiple regression analysis yielded statistically significant results, with ethical leadership explaining 15\% of the variance in hope and optimism $(\mathrm{F}(1,1661)=286.44$, $p<0.001)$. With the addition of person-organisation fit, the

TABLE 1: Descriptive statistics, Cronbach's alpha coefficients and the results of the convergent and discriminant validity analysis of the instruments.

\begin{tabular}{|c|c|c|c|c|c|c|c|c|}
\hline \multirow[t]{2}{*}{ Statistic } & \multicolumn{4}{|c|}{ Ethical leadership (seven-point Likert scale) } & \multicolumn{3}{|c|}{ Person-organisation fit (five-point Likert scale) } & \multirow{2}{*}{$\begin{array}{l}\text { Hope and optimism } \\
\text { (six-point Likert scale) }\end{array}$} \\
\hline & M\&F & RCL & PSL & Total & SF & CF & Total & \\
\hline Mean & 4.48 & 4.99 & 4.43 & 4.63 & 3.50 & 3.63 & 3.57 & 4.51 \\
\hline SD & 1.24 & 1.38 & 1.12 & 1.09 & 0.92 & 0.78 & 0.74 & 0.74 \\
\hline Skewness & -0.12 & -0.57 & -0.13 & -0.30 & -0.57 & -0.87 & -0.57 & -0.64 \\
\hline Kurtosis & -0.46 & -0.24 & -0.34 & -0.41 & 0.02 & 1.07 & 0.59 & 1.48 \\
\hline$\alpha$ & 0.84 & 0.93 & 0.86 & 0.93 & 0.91 & 0.87 & 0.89 & 0.86 \\
\hline$C R$ & 0.87 & 0.94 & 0.86 & 0.96 & 0.91 & 0.84 & 0.92 & 0.85 \\
\hline AVE & 0.55 & 0.75 & 0.56 & 0.61 & 0.77 & 0.48 & 0.58 & 0.42 \\
\hline MSV & 0.52 & 0.60 & 0.51 & 0.60 & 0.65 & 0.47 & 0.55 & 0.39 \\
\hline ASV & 0.27 & 0.45 & 0.30 & 0.23 & 0.59 & 0.28 & 0.33 & 0.20 \\
\hline
\end{tabular}

Note: All Likert scales are in a positive direction, with 1 being negative and the maximum (thus $5 / 6 / 7$ for the respective instruments) being positive.

M\&F, morality and fairness; RCL, role clarification leadership; PSL, power sharing leadership; SF, supplementary fit, CF, complementary fit. 
model improves by $8 \%$ (total variance explained is $23 \%$ ), with $\mathrm{F}(1,1660)=250.74(p<0.001)$.

The results of the stepwise multiple regression thus support the research purpose as they show that ethical leadership and person-organisation fit combined explain a significant amount of the variance in hope and optimism. Subsequently, to determine the relative strength of the independent variables (ethical leadership and person-organisation fit) in the prediction of hope and optimism, the beta coefficients $(\beta)$ were determined. The results are reported in Table 4 .

The tolerance value is 0.79 and the VIF value is 1.27 , indicating non-multicollinearity between the two independent variables, in this instance ethical leadership and person-organisation fit. Thus, although ethical leadership and person-organisation fit are correlated (see Table 2), they can still be used independently of each other with a substantial degree of accuracy. It was found that the best predictor of hope and optimism is ethical leadership $(\beta=0.23, p \leq 0.001)$ with person-organisation fit $(\beta=0.33, p \leq 0.001)$.

One of the objectives of this study was to determine the possible mediating effect of person-organisation fit on the relationship between ethical leadership and hope and optimism. Table 5 presents a summary of the mediation analysis.

TABLE 2: Correlation matrix of the factors and total scores of ethical leadership person-organisation fit and hope and optimism (all correlations are significant at $p \leq 0.001)$.

\begin{tabular}{lcccccccc}
\hline Variable & M\&F & RCL & PSL & EL & SF & CF & PoF & H\&O \\
\hline M\&F & 1 & - & - & - & - & - & - & - \\
RCL & 0.64 & 1 & - & - & - & - & - & - \\
PSL & 0.64 & 0.65 & 1 & - & - & - & - & - \\
EL & 0.87 & 0.89 & 0.86 & 1 & - & - & - & - \\
SF & 0.40 & 0.34 & 0.38 & 0.42 & 1 & - & - & - \\
CF & 0.33 & 0.31 & 0.36 & 0.38 & 0.51 & 1 & - & - \\
PoF & 0.42 & 0.38 & 0.43 & 0.46 & 0.89 & 0.85 & 1 & - \\
H\&O & 0.37 & 0.35 & 0.32 & 0.39 & 0.34 & 0.43 & 0.44 & 1 \\
\hline
\end{tabular}

M\&F, morality and fairness; RCL, role clarification leadership; PSL, power sharing leadership; EL, ethical leadership total score; SF, supplementary fit, CF, complementary fit; PoF, personorganisation fit total score; H\&O, hope and optimism.
There was a significant indirect effect of ethical leadership on hope and optimism through person-organisation fit, $a b=0.10, \mathrm{CI}$ $[0.08 ; 0.21]$. The mediator could account for roughly $38 \%$ of the total effect, $P_{\mathrm{M}}=0.38$.

Finally, to confirm the model (as depicted in Figure 1), a SEM was conducted. The results indicated a good fit $\left(\chi^{2}=1980\right.$, $d f=446, \chi^{2 / d f}=4.44, p<0.001, I F I=0.96, T L I=0.95, C F I=0.96$, RMSEA $=0.046)$. This result supports the purpose of the research, as it was found that person-organisation fit causes mediation in hope and optimism and ethical leadership. Personorganisation fit thus partially explains the relationship between the hope and optimism and ethical leadership and can be regarded as an intervening variable.

\section{Ethical consideration}

Ethical approval was obtained from the Graduate School of Business Leadership, University of South Africa, with ethical clearance number: 2016_SBL_001_CA, 2016.

\section{Discussion}

Ethical leadership is globally regarded as lacking, resulting in a plethora of negative outcomes, including feelings of hopelessness and pessimism. This study examines the relationship between the opposites of such shortcomings, namely the perception of ethical leadership (as macro variable) and optimism and hope (as micro or outcome variables). The study further aims to determine the mediating effect of PO fit as meso or intervening variable. The decision to undertake this specific study and the variables selected was based on the premise that, through a positive perception of ethical leadership, employees will be loyal and will have confidence in their leaders, which will lead to such employees being more hopeful, optimistic and positive about their work and organisation.

This study was approached from a multilevel perspective, more specifically from the micro-meso-macro framework.

TABLE 3: Results of stepwise multiple regression analysis with hope and optimism as dependent variable and the ethical leadership and person-organisation fit constructs as independent variables.

\begin{tabular}{|c|c|c|c|c|c|c|c|c|c|}
\hline \multirow[t]{2}{*}{ Model } & \multirow[t]{2}{*}{$R$} & \multirow[t]{2}{*}{$R^{2}$} & \multirow[t]{2}{*}{ Adjusted $R^{2}$} & \multirow[t]{2}{*}{ Standard error of the estimate } & \multicolumn{5}{|c|}{ Change statistics } \\
\hline & & & & & $R^{2}$ change & $F$ change & $d f^{1}$ & $d f^{2}$ & Significant $F$ change \\
\hline 1 & $0.38 \dagger$ & 0.15 & 0.15 & 0.68 & - & 286.44 & 1 & 1661 & $\leq 0.001$ \\
\hline 2 & $0.48 \%$ & 0.23 & 0.23 & 0.65 & 0.08 & 250.74 & 1 & 1660 & $\leq 0.001$ \\
\hline
\end{tabular}

$d f$, degrees of freedom.

$\dagger$, (Constant), Ethical leadership; $\$$, (Constant), Ethical leadership.

TABLE 4: The relative predictive strength of the ethical leadership and person-organisation fit (in terms of the beta values) on and hope and optimism, well as multicollinearity between them, by means of a stepwise multiple regression analysis.

\begin{tabular}{|c|c|c|c|c|c|c|c|}
\hline \multirow[t]{2}{*}{ Model } & \multicolumn{2}{|c|}{ Unstandard coefficients } & \multirow{2}{*}{$\begin{array}{c}\text { Standard coefficients } \\
\boldsymbol{\beta}\end{array}$} & \multirow[t]{2}{*}{$t$} & \multirow[t]{2}{*}{ Significance } & \multicolumn{2}{|c|}{ Collinearity statistics } \\
\hline & $\beta$ & Standard error & & & & Tolerance & Variance inflation factor \\
\hline (Constant) & 2.62 & 0.07 & - & 10.16 & $\leq 0.001$ & - & - \\
\hline Ethical leadership & 0.16 & 0.02 & 0.23 & 13.44 & $\leq 0.001$ & 0.79 & 1.27 \\
\hline Person-organisation fit & 0.33 & 0.02 & 0.33 & 10.16 & $\leq 0.001$ & 0.79 & 1.27 \\
\hline
\end{tabular}

TABLE 5: Summary of mediation analysis with a bootstrap confidence interval of $95.00 \%$, per sample of 1663 .

\begin{tabular}{|c|c|c|c|c|c|c|c|}
\hline $\begin{array}{l}\text { Independent variable } \\
\text { (predictor) }\end{array}$ & $\begin{array}{l}\text { Dependent variable } \\
\text { (Outcome variable) }\end{array}$ & $\begin{array}{l}\text { Mediated effect of person- } \\
\text { organisation fit: Product of } a \text { and } b\end{array}$ & $\begin{array}{c}\text { Path c } \\
\text { (total effect) }\end{array}$ & $\begin{array}{c}\text { Path } \mathrm{c}^{\prime} \\
\text { (direct effect of } \mathrm{X} \text { on } \mathrm{Y} \text { ) }\end{array}$ & $\begin{array}{l}\text { Direct effect } \\
\text { (X on } Y) P\end{array}$ & $\begin{array}{c}\text { Boot LLCI } \\
\text { (indirect effect) }\end{array}$ & $\begin{array}{c}\text { Boot ULCl } \\
\text { (indirect effect) }\end{array}$ \\
\hline Ethical leadership & Hope and optimism & 0.10 & 0.26 & 0.16 & $\leq 0.001$ & 0.08 & 0.12 \\
\hline
\end{tabular}


This supports the notion of Dawkins (2014) who postulates that studies need to focus on the alignment between theory, conceptualisation and operationalisation of psychological capital (which consists of four general dimensions, including hope and optimism), through the utilisation of a multilevel approach. Very little research was found that describes the relationship between the variables, although some were found in terms of related variables. Examples are studies that reported a positive relationship between authentic leadership (which has an ethical component) and psychological capital and its dimensions. Ethical leadership was found to have a positive relationship with psychological well-being and life satisfaction, which is related to psychological capital. Ethical climate (which is related to ethical leadership) was reported to have a positive relationship with employees' moral development fit and organisational commitment, and a lower employee turnover intention.

Ethical leadership, person-organisation fit and hope and optimism were measured with the ELQ (De Hoogh \& Den Hartog 2008), the PO fit questionnaire (Cable \& Judge 1996) and a section of the psychological capital questionnaire (Luthans et al. 2007). Ethical leadership consisted of morality and fairness, role clarification leadership and power sharing leadership, while person-organisation fit consisted of two dimensions, namely supplementary fit and complementary fit.

The results of the correlational analysis indicated that a positive and statistically significant $(p \leq 0.001)$ relationship exists between ethical leadership (and its sub-factors), personorganisation fit and hope and optimism (medium effect). The multiple regression, with hope and optimism as dependent variable and the ethical leadership and person-organisation fit constructs as independent variables, yielded statistically significant $(p<0.001)$ results. It was found that the best predictor of hope and optimism is ethical leadership $(\beta=0.23)$ with person-organisation fit, $\beta=0.33$ (both with $p \leq 0.001$ ). Ethical leadership explained $15 \%$ of the variance in hope and optimism and the model improved by $8 \%-23 \%$ with the addition of person-organisation fit.

The mediation analysis also yielded statistically significant results, accounting for a mediating effect of roughly $38 \%$, thus the indirect effect of ethical leadership on hope and optimism through person-organisation fit. The model was further assessed by means of SEM, resulting in a confirmation that person-organisation fit mediates the relationship between ethical leadership and hope and optimism.

The value and contribution of this study is in terms of the model that was developed and confirmed. Practically, this study contributes in terms of the identification and confirmation of variables that impact on hope and optimism in the workplace. These results could be used to make practical recommendations to enhance hope and optimism, which is regarded to be an important element of employee wellness, satisfaction, and so on.

\section{Conclusion Recommendations}

Practical recommendations are formulated in accordance with the constructs' measures, specifically ethical leadership and person-organisation fit (and its sub-factors), and the work of Luthans and Jensen (2002), Luthans et al. (2004) and Avey (2014).

In line with the notion of role clarification leadership, and the nature of hope and optimism, organisational and personal goals should be clear, specific and challenging, with measurable targets. Planning should be done in a participative manner, sharing ideas and ensuring that contingency plans or alternative pathways are in place as part of planning for 'what if' scenarios. Continuous feedback should also be provided so as to ensure that employees see their role in and contribution towards the attainment of the goal. Finally, opportunities should be created for rethinking the goals and plans and for the planning of alternative pathways.

In terms of the institutional functions, interventions can be developed by the human resource development function on individual (employees, leaders, etc.) or team level, as well as at organisation level. General training of leaders and employees that is focused on the enhancement of employee psychological capital (and specifically hope and optimism) will improve not only leadership effectiveness, but also employee well-being, employee productivity and, ultimately, according to literature and various scholars, organisational performance.

Recommendations for leaders are to allow employees to participate in decision-making and goal setting, and to stimulate and encourage self-reflection. Leaders can ensure that they obtain the necessary exposure (for instance through training, as well as coaching) in terms of different models of hopeful thoughts, and thereby build their capacity and ability to establish and institutionalise alternative ways.

It is further recommended that additional research be conducted in terms of the determination of the relationship that other leadership styles and mediators have on hope and optimism, and also on psychological capital in general. It is recommended too that different methodologies be applied, for instance longitudinal and more qualitative research designs to study the causality of these relationships.

\section{Limitations}

The limitations of this study are mainly in relation to the methodology used. The measures were based on selfreporting, which might contribute to common method bias. The Harman single factor procedure was used to determine common method bias, but it does have limitations. This may be a reality, even with the assurance provided to participants during the briefing regarding anonymity and confidentiality. Social desirability and subsequent response bias will always remain a concern and a limitation in studies such as this one, 
while self-reporting may be seen as a one-sided report from the respondents' side. A further limitation of this study is the drawback of having used a cross-sectional design which might have artificially increased the relationship between the three components.

\section{Acknowledgements Competing interests}

The authors have declared that no competing interests exist.

\section{Authors' contributions}

Both authors contributed equally to the writing of the article.

\section{Funding information}

This research received no specific grant from any funding agency in the public, commercial or not-for-profit sectors.

\section{Data availability statement}

Data sharing is not applicable to this article as no new data were created or analysed in this study.

\section{Disclaimer}

The views and opinions expressed in this article are those of the authors and do not necessarily reflect the official policy or position of any affiliated agency of the authors.

\section{References}

Ambrose, M.L., Arnaud A. \& Schminke, M., 2007, 'Individual moral development and ethical climate: The influence of person-organizational fit on job attitudes', Journa of Business Ethics 77, 323-333. https://doi.org/10.1007/s10551-007-9352-1

Arthur, W., Bell, S.T., Villado, A.J. \& Doverspike, D., 2006, 'The use of personorganization fit in employment decision making: An assessment of its criterionrelated validity', Journal of Applied Psychology 91(4), 786-801. https://doi. org/10.1037/0021-9010.91.4.786

Avey, J.B., 2014, 'The left side of psychological capital: New evidence on the antecedents of PsyCap', Journal of Leadership \& Organizational Studies 21(2), 141-149. https://doi.org/10.1177/1548051813515516

Bedi, A., Alpaslan, C.M. \& Green, S., 2015, 'A meta-analytic review of ethical leadership outcomes and moderators', Journal of Business Ethics 139, 517-536. https://doi. org/10.1007/s10551-015-2625-1

Brown, M.E., Trevino, L.K. \& Harrison, D., 2005, 'Ethical leadership: A social learning perspective for construct development and testing', Organizational Behavior and Human Decision Processes 97, 117-134. https://doi.org/10.1016/j.obhdp. 2005.03.002

Byrne, B., 2010, Structural equation modelling with AMOS: Basic concepts, applications, and programming, Lawrence Erlbaum Associates, Mahwah, NJ.

Cable, D.M. \& Judge, T.A., 1996, 'Interviewers' perceptions of person-organization fit and organizational selection decisions', Journal of Applied Psychology 82, 546-561. https://doi.org/10.1037/0021-9010.82.4.546

Cameron, K.S., Dutton, J.E. \& Quinn, R., 2003, Positive organizational scholarship, Berrett-Koehler, San Francisco, CA.

City Press, 2018, SA's business leaders aren't very optimistic, new survey shows, viewed 05 September 2018, from https://city-press.news24.com/Business/sasbusiness-leaders-arent-very-optimistic-new-survey-shows-20180124.

Ciulla, J.B., 1995, 'Leadership ethics: Mapping the territory', Business Ethics Quarterly 5(1), 5-28. https://doi.org/10.2307/3857269

Clark, L.A. \& Watson, D., 1995, 'Constructing validity: Basic issues in objective scale development', Psychological Assessment 7, 309-319. https://doi.org/10.1037/ 1040-3590.7.3.309

Dawkins, S.L., 2014, 'New directions in psychological capital research: A critical analysis and theoretical and empirical extensions to individual and team-leve measurement', Doctor of Philosophy, University of Tasmania.

De Hoogh, A.H.B. \& Den Hartog D.N., 2008, 'Ethical and despotic leadership, relationships with leader's social responsibility, top management team effectiveness and subordinates' optimism: A multi-method study', The Leadership Quarterly 19, 297-311. https://doi.org/10.1016/j.leaqua.2008.03.002
Dopfer, K., 2005, The evolutionary foundations of economics, Cambridge University Press, Cambridge.

Dopfer, K., Foster, J. \& Potts, J., 2004, 'Micro-meso-macro', Journal of Evolutionary Economics 14(3), 263-279. https://doi.org/10.1007/s00191-004-0193-0

Dopfer, K. \& Potts, J., 2008, The general theory of economic evolution, Routledge, London.

Du Plessis, M., 2014, 'The relationship between authentic leadership, psychological capital, followership and work engagement', Doctor Philosophiae in the Department of Industrial Psychology, University of the Western Cape.

Eichhorn, B.R., 2014, Common method variance techniques, Paper AA11-2014, Cleveland State University, Cleveland, $\mathrm{OH}$.

Grobler, A., 2016, 'PoF: A revised structural configuration', Journal of Applied Business Research 32(5), 1419-1434. https://doi.org/10.19030/jabr.v32i5.9769

Grobler, A., 2017, 'The measurement of ethical leadership from an et(h)ic position', African Journal of Business and Economic Research 12(2/3), 177-209. https://doi. org/10.31920/1750-4562/2017/v12n2_3a6

Grobler, A. \& Joubert, Y.T., 2018, 'PsyCap: Convergent and discriminant validity of a reconfigured measure', South African Journal of Economic and Management Sciences 21(1), a1715. https://doi.org/10.4102/sajems.v21i1.1715

Haenlein, M. \& Kaplan, A.M., 2004, 'A beginner's guide to partial least squares analysis', Understanding Statistics 3(4), 283-297. https://doi.org/10.1207/ s15328031us0304_4

Hair, J.F., Black, W.C., Babin, B.J. \& Anderson, R.E., 2010, Multivariate data analysis. A global perspective, 7th edn., Pearson, Boston, MA.

Hayes, A.F. \& Rockwood, N.J., 2017, 'Regression-based statistical mediation and moderation analysis in clinical research: Observations, recommendations, and implementation', Behaviour Research and Therapy 98, 39-57. https://doi. org/10.1016/j.brat.2016.11.001

Helland, M.R. \& Winston, B.E., 2005, 'Towards a deeper understanding of hope and leadership', Journal of Leadership and Organizational Studies 12(2), 42-54. https://doi.org/10.1177/107179190501200204

Holder, M., 2019, 'Followers say they want leaders with integrity, but do they?', The Journal of Student Leadership 2(2), 1-11.

House, R., Rousseau, D.M. \& Thomas-Hunt, M., 1995, 'The meso paradigm: A framework for the integration of micro and macro organizational behaviour', Research in Organizational Behaviour 17, 71-114.

Jahanara, M., 2017, ‘Optimism, hope and mental health: Optimism, hope, psychological well-being and psychological distress among students, University of Pune, India', International Journal of Psychological and Behavioral Sciences 11(8), 452-455.

Jeurissen, R., 1997, 'Integrating micro, meso and macro levels in business ethics', Ethical Perspectives 4(2), 246-254. https://doi.org/10.2143/EP.4.4.562986

Kanungo, R.N., 2001, 'Ethical values of transactional and transformational leaders', Canadian Journal of Administrative Sciences 18, 257-265. https://doi.org/ 10.1111/j.1936-4490.2001.tb00261.x

Kodish, S., 2006, 'The paradoxes of leadership: The contribution of Aristotle', Leadership 2, 451-468. https://doi.org/10.1177/1742715006069175

Kristof-Brown, A.L., 2000, 'Perceived applicant fit: Distinguishing between recruiters' perceptions of person-job and person-organization fit', Personnel Psychology 53, 643-671. https://doi.org/10.1111/j.1744-6570.2000.tb00217.x

Kyriakidou, O. \& Özbilgin, M.F., 2006, 'Introduction', in O. Kyriakidou \& M.F. Özbilgin (eds.), Relational perspectives in organizational studies: A research companion, pp. 1-7, Edward Elgar, Northampton, MA.

Leroy, H., Palanski, M.E. \& Simons, T., 2012, 'Authentic leadership and behavioura integrity as drivers of follower commitment and performance', Journal of Business Ethics 107, 255-264. https://doi.org/10.1007/s10551-011-1036-1

Li, L., 2006, 'The interactions between person-organization fit and leadership styles in Asian firms, an empirical testing', The International Journal of Human Resource Management 17(10), 1689-1706. https://doi.org/10.1080/09585190600964343

Lindeque, B., 2018, South Africa tops the Forbes list as the one of the world's most optimistic countries about 2018, GoodThingsGuy, viewed 05 September 2018 from https://www.goodthingsguy.com/business/optimistic-south-africa/.

Liu, B., Liu, J. \& Hu, J., 2010, 'Person-organization fit, job satisfaction, and turnover intention: An empirical study in the Chinese Public Sector', Social Behavior and Personality 38(5), 615-626. https://doi.org/10.2224/sbp.2010.38.5.615

Lu, X., Xie, B. \& Guo, Y., 2018, 'The trickle-down of work engagement from leader to follower: The roles of optimism and self-efficacy', Journal of Business Research 84, 186-195. https://doi.org/10.1016/j.jbusres.2017.11.014

Luthans, F., 2002, 'The need for and meaning of positive organizational behavior', Journal of Organizational Behavior 23, 695-706. https://doi.org/10.1002/job.165

Luthans, F. \& Avolio, B., 2003, 'Authentic leadership development', in K.S. Cameron, J.E. Dutton \& R.E. Quinn (eds.), Positive organizational scholarship, BerrettKoehler, San Francisco, CA.

Luthans, F. \& Jensen, S.M., 2002, 'Hope: A new positive strength for human resource development', Human Resource Development Review 1(3), 304-322. https://doi. org/10.1177/1534484302013003

Luthans, F., Van Wyk, R. \& Walumbwa, F.O., 2004, 'Recognition and development of hope for South African organizational leaders', The Leadership \& Organization Development Journal 25(6), 512-527. https://doi.org/10.1108/0143773 0410556752

Luthans, F., Youssef, C.M. \& Avolio, B.J., 2007, PsyCap: Developing the human competitive edge, Oxford University Press, Oxford. 
Owens, A.J., 2017, 'The relationship between authentic leadership and positive psychological capital and the moderating effects of professional development and gender in a public organization', Doctor of Education in Organizational Leadership, gender in a public organ
Pepperdine University.

Palanski, M.E. \& Yammarino, F.J., 2007, 'Integrity and leadership: Clearing the conceptual confusion', European Management Journal 25(3), 171-184. https:// doi.org/10.1016/j.emj.2007.04.006

Pallant, J., 2013, SPSS survival manual: A step by step guide to data analysis using (4th edition). Open University Press.

Perera, H.N. \& Mcllveen, P., 2014, 'The role of optimism and engagement coping in college adaptation: A career construction model', Journal of Vocational Behavio 84(3), 395-404. https://doi.org/10.1016/j.jvb.2014.03.002

Pervin, L.A. \& Rubin, D.R., 1967, 'Student dissatisfaction with college and the college dropout: A transactional approach', Journal of Social Psychology 72, 285-95. https://doi.org/10.1080/00224545.1967.9922326

Peterson, C.M. \& Seligman, M.E.P., 2003, 'Positive organizational studies: Lesson from positive psychology', in K.S. Cameron, J.E. Dutton \& R.E. Quinn (eds.), Positive organizational scholarship, pp. 14-27, Berrett-Koehler, San Francisco, CA.

Podsakoff, P.M., MacKenzie, S.B., Lee, J.Y. \& Podsakoff, N.P., 2003, 'Common method biases in behavioural research: A critical review of the literature and recommended
remedies', Journal of Applied Psychology 88(5), 879-903. https://doi.org/ remedies', Journal of Applied
10.1037/0021-9010.88.5.879

Posner, B.Z., 1992, 'Person-organisation values congruence: No support for individual difference as a moderating influence', Human Relations 45(4), 351-61. https:// doi.org/10.1177/001872679204500403

Rand, K.L., Martin, A.D. \& Shea, A.M., 2011, 'Hope, but not optimism, predicts academic performance of law students beyond previous academic achievement', Journal of Research in Personality 45, 683-686. https://doi.org/10.1016/j. jrp.2011.08.004

Reddy, J., 2017, 'South Africa urgently needs ethical leaders', Mail and Guardian, 04 May 2017.

Rego, A., Marques, C., Leal, S., Sousa, F. \& Cunha, P.M., 2010, 'Psychological capital and performance of Portuguese civil servants: Exploring neutralizers in the context of an appraisal system', The International Journal of Human Resource Management 21(9), 1531-1552. https://doi.org/10.1080/09585192.2010.488459

Resick, C.J., Hanges, P.J., Dickson, M.W. \& Mitchelson, J.K., 2006, 'A cross-cultural examination of the endorsement of ethical leadership', Journal of Business Ethics 63, 345-359. https://doi.org/10.1007/s10551-005-3242-1

Scheier, M.F. \& Carver, C.S., 1985, 'Optimism, coping and health: Assessment and implications of generalized outcome expectancies', Health Psychology 4, 219-247.
Schneider, B., Smith, D.B. \& Paul, M.C., 2001, 'P-E fit and the attraction-selectionattrition model of organizational functioning: Introduction and overview', in M Erez, U. Kleinbeck \& H. Thierry (eds.), Work motivation in the context of a globalizing economy, pp. 231-246, Erlbaum, Mahwah, NJ.

Seligman, M.E., 2011, Learned optimism: How to change your mind and your life, Random House, New York.

Shade, P., 2001, Habits of hope: A pragmatic theory, Vanderbilt University Press, Nashville, TN.

Snyder, C.R., 2002, 'Hope theory: Rainbows in the mind', Psychological Inquiry 13, 249-275. https://doi.org/10.1207/S15327965PLI1304_01

Toor, S.R. \& Ofori, G., 2009, 'Ethical leadership: Examining the relationships with full range leadership model, employee outcomes, and organizational culture', Journal of Ethics Business 90, 533-548. https://doi.org/10.1504/IJHRDM.2008.018787

Toor, S.R. \& Ogunlana, S.O., 2008, 'Leadership skills and competencies for crosscultural construction projects', International Journal of Human Resources Development and Management 8(3), 192-215.

Trevino, L.K. \& Brown, M.E., 2004, 'Managing to be ethical: Debunking five business ethics myths', Academy of Management Executive 18, 69-81. https://doi. org/10.5465/ame.2004.13837400

Tuckey, M.R., Bakker, A.B. \& Dollard, M.F., 2012, 'Empowering leaders optimize working conditions for engagement: A multilevel study', Journal of Occupational Health Psychology 17(1), 15-27. https://doi.org/10.1037/a0025942

Valentine, S., Godkin, L. \& Lucero, M., 2002, 'Ethical context, organizational commitment, and person-organization fit', Journal of Ethics Business 41, 349-360. https://doi.org/10.1023/A:1021203017316

West, S.G., Finch, J.F. \& Curran, P.J., 1995, 'Structural equation models with non-normal variables: Problems and remedies', in R.H. Hoyle (ed.), Structural equation modelling: Concepts, issues, and applications, pp. 159-176, Sage, Thousand Oaks, CA.

Yang, C., 2013, 'Does ethical leadership lead to happy workers? A study on the impact of ethical leadership, subjective well-being and life happiness in the Chinese culture', Journal of Business Ethics 123, 513-525. https://doi.org/10.1007/ s10551-013-1852-6

Youssef, C.M. \& Luthans, F., 2011, 'Positive psychological capital in the workplace: Where we are and where we need to go', In K.M. Sheldon, T.B. Kashdan \& M.F. Steger (eds.), Designing positive psychology: Taking stock and moving forward, pp. 351-364, Oxford University Press, New York.

Zhao, X., Lynch, J.G. \& Chen, Q., 2010, 'Reconsidering Baron and Kenny: Myths and truths about mediation analysis', The Journal of Consumer Research 37(2), 197-206. https://doi.org/10.1086/651257 